put into the hands of postgraduate students to fire their enthusiasm for the field, but regrettably, it is doubtful whether there are any who can afford to pay the price asked.

K. Stewartson

\section{PALAEONTOLOGICAL TECHNIQUES}

\section{Handbook of Paleontological Techniques}

Edited by Bernhard Kummel and David Raup. Pp. xiii + 852. (San Francisco and London: W. H. Freeman and Co., 1965.) 130s.

$\mathrm{P}$ ALAEONTOLOGICAL techniques, in the broadest sense, include searching for fossils, their collection, preparation, examination and eventual publication. Examination includes physical activities such as measurement, drawing and photography, and matters such as statistics and taxonomy. Publication involves writing and illustration. There is also storage and cataloguing. Palaeontologists generally work out methods suited to the fossils they are investigating by a combination of common sense and trial and error, although the larger museums and university departments have built up a repertory of techniques. There seems to have been an increasing number of new methods in recent years, taking advantage of new apparatus and materials, but most of the basic techniques and a number of specialized ones have been known a long time. Many papers describe individual techniques, but there has been no complete guide since the modest book by Camp and Hanna (Methods in Paleontology, University of California Press, 1937), which gave useful accounts of many techniques, with emphasis on vertebrates and micropalaeontology. Handbook of Paleontological Techniques is a new attempt to cover a field nearly as wide as that defined at the head of this paragraph.

The book consists of five parts: (1) procedures and techniques applicable to major fossil groups; (2) descriptions of specific techniques; (3) techniques in palynology (the study of pollen); (4) bibliography on palaeontological techniques; (5) list of bibliographies of stratigraphy and palaeontology. Each part consists of a number of short articles. Part 1 includes 21 essays covering most of the major fossil groups, although the ammonoids are a conspicuous omission. The essays range from chatty personal reminiscences to systematic notes on collecting and prepara. tion. For the reader seeking practical information this is possibly the least useful part of the book, although several papers, notably that on ostracods, describe techniques in detail.

Part 2 is divided into sections on collecting, mechanical and chemical preparation, radiation techniques, casting and illustration. Most of the 13 articles in the section on collecting are either elementary (with remarks such as "Fossils are most commonly found in sediments or sedimentary rocks") or very specialized. The section on mechanical preparation has two omissions. Mechanical chisels have long been used at some laboratories, but it has been difficult to get satisfactory apparatus. An account of available machines, or constructional details, would have been useful, but only the Burgess vibro-tool is mentioned. Many makes of ultrasonic cleaning gear are now available and the palaeontologist needs guidance as to the merits of different frequencies, wide or narrow frequency ranges and different powers for cleaning fossils, but this is not given. The section on chemical methods is short (two papers) and deals only with acid treatment.

The section on radiation techniques is a good introduction for the worker contemplating the use of X-rays, ultra-violet or infra-red light, or electron microscopy in the examination of his fossils. The section on casting and moulding also gives a good account of the chief materials and methods. A fuller account of materials used for impregnating friablo fossils would have been worth while.
Four of the seven articles on illustration are concerned with photography. There is also an account of ways of whitening fossils for photography, but some of the material in it is repeated in other articles throughout the book. This kind of duplication unfortunately affects a number of topics, for example micropalaeontology. The article on preparation of plates for publication is less useful than the notes for authors issued by the Palaeontological Association.

Part 3 seems to cover the specialized subject of palynology thoroughly. It occupies, however, no less than onethird of the book, an unduly large proportion. There would have been a case for devoting other parts of the book to major branches of the subject. Micropalaeontology occu. pies about 130 pages scattered through the book. Would it not have been better to bring this material together? As it is, the information in the book is assembled partly under techniques and partly under fossil groups, which results in duplication.

Statistics might legitimately have been included. There is a useful article on sampling, but the only other paper on statisties is in the palynology section and has mathematics beyond most pal«eontologists. Similarly, zoological nomenclature concerns every palaeontologist, and an exposition of the main points of the latest rules of nomenclature would have been handy.

The difficulties of co-ordinating the work of $80 \mathrm{con}$ tributors are obvious. One wonders whethor so many were really necessary, and whether a smaller number might not have resulted in a more compact, equally useful, book at a lower price.

D. T. Donovan

\section{SOME ASPECTS OF BORON}

Boron, Metallo-Boron Comfounds and Boranes

Edited by Roy M. Adams. Pp. xxiii +765 . (New York and London: Interscience Publishers, a Division of John Wiley and Sons, 1964.) 207s.

THE present upsurge of interest in the chemistry of boron-until 10 or 15 years ago a very neglected element-has created a genuine need for the recently amassed knowledge to be made reedily available to the enquirer and for the demands of teachers and research workers in purticular to be supplied. Fortunately the compilers of such volumes have not been idle, and several unrelated books about boron have appeared in recent years, not one of which, however, provides us with a comprehensive account of the chemistry of the element as a whole and in true perspective. For this we must writ; and, indeed, there are so many new and unoxpocted fundamental facts about the element still being discovered that it is doubtful whether such a volume (or volumes) would be well timed to appes at the present moment. We must therefore be all the more grateful for the appearance of books that deal well with certain aspects of boron chemistry, of which Boron, Metallo-Boron Compounds and Boranes is an excellent example.

This book is in fact a collection of eight reviews by several experts, under the general editorship of the principal contributor, Roy M. Adams. In spite of a certain unevenness - - the first two reviews are relatively slightthe imput of the book as a whole is considerable, the result of careful scholarship. The scope of tho book is perhaps best conveyed by its chapter headings, which are: "History and Technology of the Borax Industry", by W. A. Gale (27 pp., 141 references); "Hoterogeneous Equilibria in Aqueous Systems of Inorganic Borates", by W. A. Gale (24 pp., 31 references); "Inorganic BoronOxygen Chemistry", by N. P. Nies and G. W. Campbell (179 pp., 980 references); "Elemental Boron", by A. E. Newkirk (67 pp., 374 references); "Refractory Binary Borides", by B. Post (71 pp., 160 references); "The Hydro- 